\title{
Brain-Derived Neurotrophic Factor and trkB Signaling in Parasympathetic Neurons: Relevance to Regulating $\alpha 7$ - Containing Nicotinic Receptors and Synaptic Function
}

\author{
Xiangdong Zhou, Qiang Nai, ${ }^{\star}$ Min Chen, ${ }^{\star}$ Jason D. Dittus, Marthe J. Howard, and Joseph F. Margiotta \\ Medical College of Ohio, Department of Anatomy and Neurobiology, Toledo, Ohio 43614-5804
}

\begin{abstract}
Parasympathetic neurons do not require neurotrophins for survival and are thought to lack high-affinity neurotrophin receptors (i.e., trks). We report here, however, that mRNAs encoding both brain-derived neurotrophic factor (BDNF) and its high-affinity receptor tropomyosin-related kinase B (trkB) are expressed in the parasympathetic chick ciliary ganglion (CG) and that BDNF-like protein is present in the ganglion and in the iris, an important peripheral target of ciliary neurons. Moreover, $C G$ neurons express surface trkB and exogenous BDNF not only initiates trk-dependent signaling, but also alters nicotinic acetylcholine receptor (nAChR) expression and synaptic transmission. In particular, BDNF applied to CG neurons rapidly activates cAMP-dependent response element-binding protein (CREB), and over the long-term selectively upregulates expression of $\alpha 7$-subunit-containing, homomeric nAChRs ( $\alpha 7$-nAChRs), increasing $\alpha 7$-subunit mRNA levels, $\alpha 7$-nAChR surface sites, and $\alpha 7$-nAChR-mediated whole-cell currents. At nicotinic synapses formed on CG neurons in culture, brief and long-term BDNF treatments also increase the frequency of spontaneous EPSCs, most of which are mediated by heteromeric nAChRs containing $\alpha 3, \alpha 5, \beta 4$, and $\beta 2$ subunits ( $\alpha 3^{*}$-nAChRs) with a minor contribution from $\alpha 7$-nAChRs. Our findings demonstrate unexpected roles for BDNF-induced, trk-dependent signaling in CG neurons, both in regulating expression of $\alpha 7$-nAChRs and in enhancing transmission at $\alpha 3^{\star}$-nAChR-mediated synapses. The presence of BDNF-like protein in CG and iris target coupled with that of functional trkB on CG neurons raise the possibility that signals generated by endogenous BDNF similarly influence $\alpha 7$-nAChRs and nicotinic synapses in vivo.
\end{abstract}

Key words: ciliary ganglion; nicotinic acetylcholine receptor; BDNF; trkB; patch-clamp; neurotrophin; bungarotoxin; EPSC; cAMP response element-binding protein (CREB); PACAP

\section{Introduction}

Neurotrophins [ nerve growth factor (NGF), brain-derived neurotrophic factor (BDNF), and neurotrophin-3 (NT-3)] act via high-affinity tyrosine kinase-containing receptors (trkA, trkB, and trkC, respectively) to support the survival and growth of diverse neuron populations and influence the form and function of chemical synapses (Lewin and Barde, 1996; Kaplan and Miller, 2000; Huang and Reichardt, 2001). In particular, BDNF and sometimes NT-3, exert rapid, primarily presynaptic effects at central, autonomic, and neuromuscular synapses and produce long-term presynaptic and postsynaptic changes consistent with

\footnotetext{
Received Jan. 7, 2004; revised March 9, 2004; accepted March 11, 2004.

This work was supported by National Institutes of Health Grants R01-DA15536 (J.F.M.) and R01-NS40644 (M.J.H.). We thank Wei Han for technical assistance, Drs. Frances Lefcort and Louis Reichardt for providing trkB and p75 NTR antisera, Dr. Xuan Zheng for advice on real-time PCR, and Drs. Darwin Berg, Leslie Henderson, and Phyllis Pugh for helpful comments on this manuscript.

${ }^{*} Q$.N. and M.C. contributed equally to this work.

Correspondence should be addressed to Dr. Joseph F. Margiotta, Medical College of Ohio, Department of Anatomy and Neurobiology, BHS 108, 3035 Arlington Avenue, Toledo, OH 43614-5804. E-mail: jmargiotta@mco.edu.

Q. Nai's present address: Department of Biology 0357, University of California, San Diego, 9500 Gilman Drive, La Jolla, CA 92093.

M. Chen's present address: Behavioral Medicine Research Institute, Ohio State University, 2187 Graves Hall, 333 West Tenth Avenue, Columbus, $\mathrm{OH} 43210$

DOI:10.1523/JNEUROSCI.0055-04.2004

Copyright (C) 2004 Society for Neuroscience $\quad 0270-6474 / 04 / 244340-11 \$ 15.00 / 0$
}

altered gene expression (for review, see Lewin and Barde, 1996; Schuman, 1999; Poo, 2001). Thus, in addition to providing trophic support, neurotrophins also induce trk-dependent acute and long-term changes that coordinately influence synaptic interactions.

Parasympathetic neurons typified by those in the chicken ciliary ganglion (CG) do not require neurotrophins for survival (Helfand et al., 1976; Rohrer and Sommer, 1982; Lindsay et al., 1985; Krieglstein et al., 1998). Instead, CG neurons rely on other growth factors, notably ciliary neurotrophic factor (CNTF) (Leung et al., 1992; Finn et al., 1998) and glial-derived neurotrophic factor (GDNF) (Hashino et al., 2001) for trophic support. Moreover, studies using Northern and RNase protection assays failed to detect trk mRNA in ciliary ganglia (Dechant et al., 1993; Hallbook et al., 1995). These observations have led to the presumption that CG neurons lack trks (Huang and Reichardt, 2001).

As with sympathetic ganglion neurons and skeletal muscle fibers, fast chemical synapses on ciliary and other parasympathetic ganglion neurons are mediated by nicotinic acetylcholine receptors (nAChRs). In sympathetic neurons, NGF supports the expression of $\alpha 3$-nAChR subunit protein (Yeh et al., 2001), an effect mirrored in pheochromocytoma cell line (PC12) cells, where NGF increases $\alpha 3, \alpha 5, \alpha 7, \beta 2$, and $\beta 4 \mathrm{nAChR}$ subunit mRNAs as well as 
nAChR function (Henderson et al., 1994; Takahashi et al., 1999). Also, sympathetic neurons overexpressing BDNF display increased preganglionic innervation density (Causing et al., 1997), indicative of long-term presynaptic effects. BDNF acting through trkB also regulates neuromuscular junction form and function. For example, BDNF rapidly enhances presynaptic release to increase the frequency and amplitude of spontaneous nAChR-mediated synaptic currents in nerve-muscle cultures (Lohof et al., 1993; Stoop and Poo, 1996). Over the long term, BDNF restores neuregulin levels, restricts axon sprouting, and maintains postsynaptic architecture in muscle disrupted by activity blockade (Loeb et al., 2002), whereas sustained trkB-mediated signaling is likely required to maintain postsynaptic nAChR clusters (Gonzalez et al., 1999). These findings prompted us to speculate that previous assays were perhaps insufficiently sensitive to detect trks expressed in ciliary ganglia and that neurotrophin-trk signaling, although not required for trophic support, might influence the components and function of nAChRmediated synapses on CG neurons. We focused on BDNF-trkB signaling, and we have demonstrated expression of BDNF-like protein in ciliary ganglia and functional trkB on CG neurons. To explore synaptic relevance, the impact of BDNF-trkB signaling on $\alpha 7$ nAChRs and $\alpha 3^{*}-\mathrm{nAChR}$-mediated synapses was assessed using CG neurons grown in cell culture. BDNF treatment upregulated expression of $\alpha 7$-nAChRs after several days and increased the frequency of spontaneous synaptic currents within minutes. The results reveal an unanticipated relevance for BDNF-trkB signaling in parasympathetic CG neurons.

\section{Materials and Methods}

Neurons. CG neuron cultures were prepared under sterile conditions from embryonic day 8 (E8) chick embryos. Dissociated neurons were plated at one or two ganglion equivalents in $15 \mathrm{~mm}$ diameter polystyrene tissue culture wells or on 12-mm-diameter glass coverslips; both substrates were precoated with poly-DL-ornithine and laminin (Pugh and Margiotta, 2000; Chen et al., 2001). The standard culture medium consisted of minimum essential medium (MEM) containing $100 \mathrm{U} / \mathrm{ml}$ penicillin, $100 \mu \mathrm{g} / \mathrm{ml}$ streptomycin, $2 \mathrm{~mm}$ glutamine, and $10 \%$ heat inactivated horse serum $\left(\mathrm{MEM}^{\mathrm{hs}}\right.$; all components from Invitrogen, Rockville, $\mathrm{MD}$ ) and was supplemented with $3 \%$ embryonic eye extract (Nishi and Berg, 1981). Neurons were maintained at $37^{\circ} \mathrm{C}$ in $95 \%$ air and $5 \% \mathrm{CO}_{2}$ for $4-7 \mathrm{~d}$ and received fresh culture medium every $2-3 \mathrm{~d}$, conditions that support $100 \%$ survival of CG neurons for at least $7 \mathrm{~d}$ (Nishi and Berg, 1981). In test cultures the medium was further supplemented with BDNF $(50 \mathrm{ng} / \mathrm{ml}$, unless indicated otherwise) sometimes in conjunction with other reagents as described for individual experiments in Results. For some studies, CG neurons were acutely dissociated from E8 or E14 ganglia, as previously described (McNerney et al., 2000; Nai et al., 2003). Neurons were plated on acid-washed, poly-D-lysine-coated glass coverslips in electrophysiological recording solution (RS) containing (in mM): $145.0 \mathrm{NaCl}, 5.3 \mathrm{KCl}, 5.4 \mathrm{CaCl}_{2}, 0.8 \mathrm{MgSO}_{4}, 5.6$ glucose, and 5.0 HEPES, pH 7.4 (Dichter and Fischbach, 1977) that was supplemented with $10 \%$ heat-inactivated horse serum $\left(\mathrm{RS}^{\mathrm{hs}}\right)$. Acutely dissociated neurons were maintained in $\mathrm{RS}^{\text {hs }}$ at $37^{\circ} \mathrm{C}$ for $2-4 \mathrm{hr}$ before use.

Conventional RT-PCR. The presence of mRNA encoding chicken trkB, BDNF, $\alpha 7$, and $\alpha 3$-nAChR subunits, as well as $\beta$-actin $(\beta \mathrm{A})$ or glyceraldehyde-3-phosphate dehydrogenase (GAPDH), was assessed by conventional reverse transcriptase-based PCR (RT-PCR) as previously described (Burns et al., 1997). Briefly, RNA was isolated from E8-E15 chick tissues or from CG neuron cultures using a one-step kit (RNAqueous; Ambion, Austin, TX). Total tissue RNA $(1 \mu \mathrm{g})$ was treated with Amplification Grade RNase-free DNase ( $1 \mathrm{U}$ at $1 \mathrm{U} / \mu \mathrm{l}$; Invitrogen), and then 25-200 ng of DNase-treated RNA used to synthesize cDNA using Superscript II reverse transcriptase (RT+; Invitrogen). The resulting cDNAs were then used as templates for PCR amplifications in $25 \mu$ reaction volumes containing $50 \mathrm{~mm} \mathrm{KCl}, 20 \mathrm{~mm}$ Tris- $\mathrm{HCl}, 2.5 \mathrm{~mm} \mathrm{MgCl}_{2}, 200 \mu \mathrm{M}$ dNTPs, $5 \mathrm{U} / \mu \mathrm{l}$ TaqDNA polymerase (Invitrogen), and $0.4 \mu \mathrm{M}$ forward (F) and reverse (R) oligonucleotide primers (synthesized by Marshall University DNA Core Facility, Huntington, WV). The chicken-specific primers used were: $\operatorname{trkB}$ (Dechant et al., 1993): $\mathrm{F}, \mathrm{C}_{1156}{ }_{\text {TTCAGCTGGACAA- }}$ CCCTAC $_{1175} ; \mathrm{R}_{\mathrm{K}}{ }^{+}, \mathrm{T}_{1868}$ GGAAGTCCTTGCGGGCATT $_{1849} ; \mathrm{R}_{\mathrm{K}}-$, GCCCCTCTCTCATCTT; BDNF (Maisonpierre et al., 1992): F, $\mathrm{G}_{287}$ CAGTCAAGTGCCTTTG $_{303} ; \mathrm{R}, \mathrm{G}_{748}$ AGCCCACTATCTTCCCC $_{731}$; $\alpha 7$-nAChR subunit (Couturier et al., 1990b): F, $\mathrm{G}_{1092}$ GGGAAAAATGCCTAAAT $_{1109} ; \mathrm{R}, \mathrm{G}_{1614}$ ACAGCCTCTACAAAGTT $_{1597} ; \alpha 3-n$ AChR subunit (Couturier et al., 1990a): F, A $_{985}$ TGCCTGTATGGGTGAGAACT $_{1005} ; \mathrm{R}_{\text {, }}$ $\mathrm{T}_{1226}$ TGCCACTGAAATCGGAAAAC $_{1206}$; GAPDH (Stone et al., 1985): $\mathrm{F}$, $\mathrm{G}_{532}$ CCATCACAGCCACACAGAA $_{551} ; \mathrm{R}, \mathrm{A}_{980}$ CCATCAAGTCCACAACACG $_{961}$; and $\beta$-actin (GenBank accession number L08165): $\mathrm{F}$, $\mathrm{A}_{860}$ TCTTTCTTGGGTATGGA $_{877} ; \mathrm{R} \mathrm{A}_{1134}$ CATCTGCTGGAAGGTCC $_{1117}$.

The two trkB primer pairs $\left(\mathrm{F} / \mathrm{R}_{\mathrm{K}}{ }^{+}\right.$and $\left.\mathrm{F} / \mathrm{R}_{\mathrm{K}}\right)$ correspond to those shown previously to amplify kinase-containing (full-length) and truncated (kinase-deleted) chicken trkB isoforms, respectively (Garner et al., 1996). The $\mathrm{F} / \mathrm{R}_{\mathrm{K}}{ }^{+}$pair is not predicted to hybridize with chicken trkA (Schropel et al., 1995) or trkC (Garner and Large, 1994) cDNAs. The $\alpha 7$ and $\alpha 3$-nAChR subunit primer pairs both amplify products within nonconserved regions of their respective cytoplasmic domains, located between transmembrane segments III and IV (Schoepfer et al., 1990). The trkB and AChR subunit primers were optimized for amplification, and the reactions were performed in the linear range of the assay (25-29 cycles). PCR products were separated on $1.0 \%$ agarose gels stained with ethidium bromide. Identical reactions lacking RT served as controls for possible amplification of genomic DNA and were consistently negative. Changes in the levels of $\alpha 7$ and $\alpha 3$ mRNAs in response to BDNF treatment were estimated semiquantitatively after digitizing gel images using Kodak 1D Image Analysis software (Eastman Kodak, Rochester, NY) from the ratio of PCR product intensities to those of $\beta$ A from the same cultures.

Real-time PCR. Changes in $\alpha 7$ - and $\alpha 3$-nAChR subunit mRNA levels induced by BDNF were confirmed using RT-based real-time PCR. cDNA samples corresponding to $50 \mathrm{ng}$ of input RNA were combined with Taqman universal PCR master mix (Roche, Branchburg, NJ), F and R primers $(0.4 \mu \mathrm{M})$, and Taqman probe $(0.1 \mu \mathrm{M})$ [with 6-FAM (carboxyfluorescein, reporter dye) and TAMRA (tetramethylrhodamine, quencher dye) inserted at $5^{\prime}$ and $3^{\prime}$ ends, respectively]. Selection of the following primers and probes was optimized using Applied Biosystems (Foster City, CA) Primer-Express software, with $\alpha 7$ - and $\alpha 3$-nAChR subunit primers chosen to amplify regions within transmembrane segments III and IV, and span intron-exon boundaries (Schoepfer et al., 1990): $\alpha 7-n A C h R$ subunit (Couturier et al., 1990b): F, $\mathrm{C}_{1020}$ CATGATTATTGTTGGCCTCTCT $_{1042}$; $\mathrm{R}, \mathrm{T}_{1210}$ CGGCCCTGTTTATGTTGAC $_{1190}$; Probe, $\mathrm{A}_{1115}$ GAGTCATCCTTCTGAATTGGTGTGCTTGGT ${ }_{1145} ; \alpha 3-n A C h R$ subunit (Couturier et al., 1990a): F, G $_{1178}$ CAGCTGCTGCCAGTACCA $_{1196} ; \mathrm{R}_{1398} \mathrm{~A}_{139}$ ATACCATGGCAACATATTTCC $_{1376}$; Probe, $\mathrm{T}_{1216}{ }_{\text {TCAGTGGCAATC- }}$ TCACAAGAAGTTCCAGC $_{1245}$; and GAPDH (Stone et al., 1985): F, $\mathrm{C}_{1795}$ CGTCCTCTCTGGCAAAGTC $_{1814} ; \mathrm{R}, \mathrm{A}_{2374}$ ACATACTCAGCACCTGCATCTG $_{2352}$; Probe, $\mathrm{A}_{2211}$ TCAATGGGCACGCCATCACTAT$\mathrm{CTTCC}_{2228}$.

Twenty-five microliter PCRs were performed in triplicate using a GeneAmp 5700 sequence detection system (Applied Biosystems). This system allows the increase in PCR product to be monitored directly based on the threshold number of cycles (CT) required to produce a detectable change in fluorescence $(\Delta \mathrm{F})$ resulting from the release of probe. Relative levels of $\alpha 7$ - and $\alpha 3$-nAChR cDNA $\left(\mathrm{R}_{\alpha 7}, \mathrm{R}_{\alpha 3}\right)$ in control and BDNF-treated cultures were calculated from the difference in CT values $\left(\Delta \mathrm{CT}=\mathrm{CT}_{\text {control }}-\mathrm{CT}_{\mathrm{BDNF}}\right)$ for $\alpha 7$ or $\alpha 3$ amplifications $\left(\Delta \mathrm{CT}_{\alpha 7}, \Delta \mathrm{CT}_{\alpha 3}\right)$ compared with those for the housekeeping gene, $\operatorname{GAPDH}\left(\Delta \mathrm{CT}_{\mathrm{GAPDH}}\right)$ using:

$$
R_{\alpha}=\left(E_{\alpha}{ }^{\Delta \mathrm{CT}_{\alpha}}\right) /\left(E_{\mathrm{GAPDH}}{ }^{\Delta \mathrm{CT}_{\mathrm{GAPDH}}}\right) .
$$

In Equation 1, $E_{\alpha}$ and $E_{\mathrm{GAPDH}}$ are the real-time PCR amplification efficiencies determined in separate studies from the slope of $C$ T versus input $\log$ cDNA dilution, where $E=10^{-1 / \text { slope }}$. $E$ values for amplifying $\alpha 7, \alpha 3$, and GAPDH cDNAs were 2.10, 2.10, and 2.23, respectively.

Immunocytochemistry. A polyclonal antibody (pAb) generated against 
the extracellular domain of chicken trkB (\#R22781) that does not recognize trkA or trkC (von Bartheld et al., 1996) was generously provided by Dr. Frances Lefcort (Montana State University). pAb recognizing Ser ${ }_{133^{-}}$ phosphorylated cAMP response element (CRE) binding protein (pCREB) was purchased from Cell Signaling Technology (Beverly, MA). Ciliary and dorsal root ganglia (DRG) were fixed for $1-4 \mathrm{hr}$ in $4 \%$ paraformaldehyde prepared in $0.15 \mathrm{~m}$ PBS at $\mathrm{pH}$ 7.4 (PBS), washed in PBS, cryoprotected in PBS containing 30\% sucrose, embedded in OCT (Miles Laboratories, Elkhardt, IN), cryosectioned at $10 \mu \mathrm{m}$, and mounted on glass slides. After rehydration, sections were blocked for $1 \mathrm{hr}$ at room temperature in $30 \mathrm{~mm}$ Tris and $150 \mathrm{~mm} \mathrm{NaCl}$ containing $0.4 \%$ Triton $\mathrm{X}-100,1 \%$ glycine, $10 \%$ goat serum, and $3 \%$ bovine serum albumin. trkB antibody $(\mathrm{Ab})$ was applied to sections in blocking solution containing $4 \%$ goat serum $\left(1: 1000,4^{\circ} \mathrm{C}, 16 \mathrm{hr}\right)$, and after washing, secondary $\mathrm{Ab}$ (AlexaFluor594-conjugated anti-rabbit IgG; Molecular Probes, Eugene, OR) was applied in the same solution $\left(1: 400,22^{\circ} \mathrm{C}, 1 \mathrm{hr}\right)$. Sections were then washed, dipped in distilled water, and mounted in Vectashield (Vector Laboratories, Burlingame, CA). Acutely dissociated CG neurons or CG neuron cultures, both on glass coverslips, were fixed for $0.5-1.0 \mathrm{hr}$ in $2-4 \%$ paraformaldehyde and blocked in PBS containing $10 \%$ donkey or goat serum. Coverslips were then incubated in trkB $\mathrm{Ab}\left(1: 2000,37^{\circ} \mathrm{C}\right.$, $2 \mathrm{hr})$ treated with Cy3-conjugated anti-rabbit $\operatorname{IgG}\left(1: 400,1 \mathrm{hr}, 37^{\circ} \mathrm{C}\right.$; The Jackson Laboratory, Bar Harbor, ME) in PBS containing 4\% serum, washed, and mounted. A similar protocol was followed for p-CREB immunostaining except that the block and wash buffers contained $0.1 \%$ Triton X-100, p-CREB Ab was applied $\left(1: 400,4^{\circ} \mathrm{C}, 16 \mathrm{hr}\right)$, and the secondary $\mathrm{Ab}$ was AlexaFluor488-conjugated anti-rabbit $\operatorname{IgG}\left(1: 400,22^{\circ} \mathrm{C}\right.$, $1 \mathrm{hr})$.

Image analysis. Immunostained preparations were viewed using epifluorescence microscopy (BX50, UplanFL 40×, 0.75 numerical aperture objective; Olympus, Tokyo, Japan), and images were acquired and processed using a SenSys KAF-1400 cooled digital CCD camera under the control of IP Lab software (version 3.6; Scanalytics, Reading, PA) as described previously (Chen et al., 2001). Neurons were considered p-CREB-positive if the mean fluorescence intensity of pixels in an elliptical region of interest (ROI) superimposed over the nucleus exceeded that of the ROI when placed over cytoplasm by $>15 \%$.

ELISAs. The presence of BDNF in chicken tissue homogenates and tissue culture medium components was assessed using a commercial BDNF sandwich ELISA kit having no significant cross-reactivity with NGF, NT4/5, or NT3 (Chemikine; Chemicon, Temecula, CA). The ELISA uses rabbit polyclonal antibodies (raised against human BDNF) to capture BDNF from the sample, and a biotinylated mouse monoclonal antibody to detect the captured BDNF. Because mammalian and chicken BDNF share all but seven amino acids, with the mismatches distributed along the entire length of the peptide (Isackson et al., 1991), the kit antibodies likely recognize chicken BDNF. Nevertheless, we refer here to detection of "BDNF-like protein," with levels quantified within the linear range of the assay $(7.8-500 \mathrm{pg} / \mathrm{ml})$ using recombinant human BDNF as standard.

$\alpha$-Bungarotoxin binding. CG neurons were plated at one or two ganglion equivalents per well and grown in culture wells for $4-5 \mathrm{~d}$. Neurons in triplicate culture wells were washed twice in MEM $^{\text {hs }}$, incubated in $\mathrm{MEM}^{\text {hs }}$ containing $10 \mathrm{nM}\left[{ }^{125} \mathrm{I}\right]-\alpha$-Bungarotoxin $(\alpha$-Bgt) (specific activity $=130-140 \mathrm{Ci} / \mathrm{mmol}$; PerkinElmer, Boston, MA) for $1 \mathrm{hr}$ at $37^{\circ} \mathrm{C}$, and then washed three times with MEM $^{\text {hs }}$. We previously showed that these conditions are sufficient to saturate surface $\alpha$-Bgt sites on dissociated CG neurons (McNerney et al., 2000). Nonspecific binding was determined in parallel wells by including $100 \mu \mathrm{M}$ D-tubocurarine with $10 \mathrm{nM}\left[{ }^{125} \mathrm{I}\right]-\alpha-$ Bgt. After labeling and washing, the wells were scraped in $500 \mu \mathrm{l} 0.6 \mathrm{~N}$ $\mathrm{NaOH}$, the solution was collected, and $\left[{ }^{125} \mathrm{I}\right]-\alpha$-Bgt radioactivity was determined using a Beckman Instruments (Fullerton, CA) G-5500 gamma counter.

Electrophysiology. Whole-cell recordings were obtained at $21-23^{\circ} \mathrm{C}$ from CG neurons after 3-5 d in culture. Patch pipettes were fabricated from Corning 8161 glass tubing (WPI, Sarasota, FL), filled with (in mM) 145.6 CsCl, 1.2 $\mathrm{CaCl}_{2}, 2.0$ EGTA, 15.4 glucose, and 5.0 Na-HEPES, pH 7.3, and had tip impedances of 2-3 M . To induce nAChR currents, neurons were bathed in $\mathrm{RS}^{\text {hs }}$, held at $-70 \mathrm{mV}$, and $20 \mu \mathrm{m}$ nicotine (Nic) applied in RS by rapid pressure microperfusion (at 10-12 psi) from a delivery pipette ( $4-6 \mu \mathrm{m}$ tip diameter) positioned $\approx 5-10 \mu \mathrm{m}$ from the neuron soma. We previously showed that fast-onset, rapidly desensitizing $\alpha 7$-nAChR-mediated whole-cell currents induced by $20 \mu \mathrm{M} \mathrm{Nic}$ in this manner are indistinguishable in amplitude from those obtained using fast piezoelectric switching (Nai et al., 2003). The fast $(\alpha 7-\mathrm{nAChR}-$ mediated) and slower $\left(\alpha 3^{\star}\right.$-nAChR-mediated) decaying current components induced by $20 \mu \mathrm{M}$ Nic were identified and analyzed using Clampfit (pClamp 6.0 or 8.0 ; Axon Instruments, Foster City, CA) as previously described (Nai et al., 2003). For analysis, peak Nic-induced response component amplitudes (in picoamperes) were normalized to neuron soma membrane capacitance (in picofarads). To quantify BDNF effects, whole-cell Nic responses (in picoamperes per picofarad) obtained from treated neurons were normalized to those for control neurons from the same cultures. To assess synaptic function, spontaneous EPSCs (sEPSCs) were acquired at $-70 \mathrm{mV}$ for $2-5 \mathrm{~min}$, without stimulation, as previously described (Chen et al., 2001). For these experiments, horse serum was sometimes omitted from the recording solution, without discernible effect on the results. Synaptic current frequency and amplitude analyses were subsequently performed using either BASIC-23 programs written in-house, or commercially available software (Mini Analysis 5.6.12; Synaptsoft Inc., Decatur, GA). Briefly, sEPSC frequency values obtained from BDNF-treated neurons were normalized to those from control neurons from the same culture platings. In addition, sEPSCs were extracted from selected records displaying $>50$ non-overlapping events, and the component amplitude and decay time constant values were pooled for control and BDNF-treated neurons.

Statistics. All parameter values are expressed as mean \pm SEM. Unless indicated otherwise, the statistical significance of paired and unpaired numerical comparisons was determined using the appropriate two-tailed $t$ test $(p<0.05)$.

\section{Results}

\section{Expression of trkB mRNA and protein}

PCR primers specific for kinase-containing $\left(\mathrm{K}^{+}\right)$full-length trkB (Garner et al., 1996) amplified $\mathrm{a} \approx 700 \mathrm{bp}$ product from both $\mathrm{E} 8$ and E14 CG cDNA templates (Fig. 1 $a, b$ ). The CG product size was consistent with that predicted for chicken trkB (713 bp) (Garner et al., 1996) and indistinguishable from that obtained in amplifications from E15 DRG, previously shown to express abundant trkB mRNA (Hallbook et al., 1995) and protein (Anderson, 1999; Rifkin et al., 2000). In addition, trkB products from E14 CG and E15 DRG yielded identical restriction profiles after digestion with BamHI (data not shown) or HbaII (Fig. 1c), with fragment sizes as predicted for digestion of $\mathrm{K}^{+} \operatorname{trkB} \mathrm{cDNA}$ (Dechant et al., 1993). Truncated trkB isoforms lacking the kinase domain $(\mathrm{K}-)$ but containing variable juxtamembrane insertions are also expressed in the chicken nervous system (Garner et al., 1996), and $\mathrm{K}-$-specific primers amplified products of expected sizes ( $\approx 400,500$, and $600 \mathrm{bp}$ ) from both DRG and CG (Fig. $1 a, b$ ). In each case, the PCR amplifications from DRG and CG sources were specific for CDNA in the sense that they were absent when the synthesis reaction lacked RT (data not shown). Although the significance of the truncated trkB transcripts was not studied here, the results demonstrate that both truncated and full-length trkB transcripts are expressed in CG during E8-E14, a developmental window when nicotinic synapses formed on the neurons undergo substantial structural and functional maturation (Landmesser and Pilar, 1972, 1974a).

The presence of trkB protein on CG neurons was demonstrated by fluorescence immunolabeling (Fig. 2) using an Ab that recognizes the extracellular domain of chicken trkB (but not trkA or trkC; von Bartheld et al., 1996). Specific trkB labeling, similar to but somewhat less intense than that seen for E15 DRG sections, was evident in both E8 and E14 CG sections (Fig. 2a,b,c,f) and was localized to the neuron surface where it increased between 
a

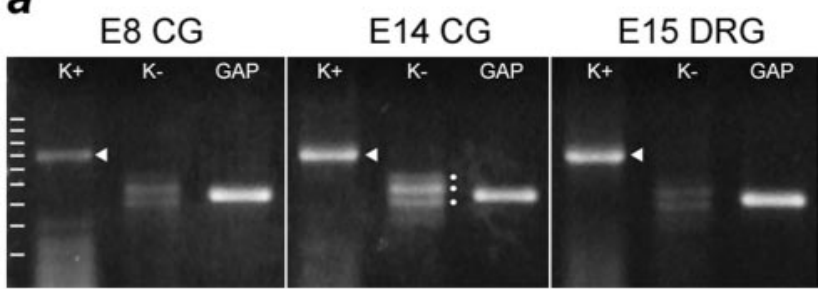

b

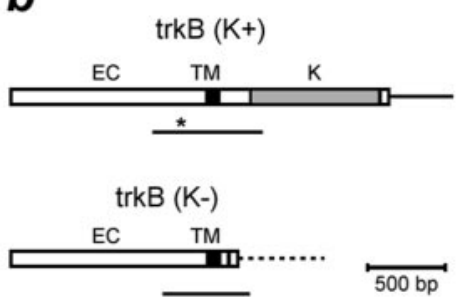

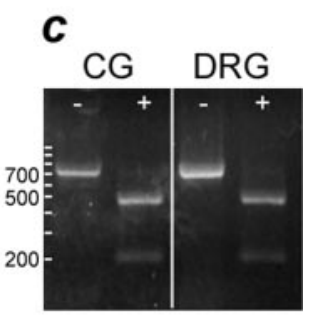

Figure 1. Detection of trkB transcripts in ciliary ganglia. $a, P C R$ amplifications were conducted on CDNAs from E8 CG, E14 CG, and E15 DRG using primer pairs specific for chicken full-length trkB $\left(\mathrm{K}^{+}\right)$, kinase-deleted trkB $(K-)$, or GAPDH (GAP), and the resulting products were separated by gel electrophoresis. Arrowheads at $\approx 700$ bp and dots at $\approx 400,500$, and 600 bp (E14 CG shown) mark product sizes expected for $\mathrm{K}^{+}$trkB and for the truncated $\mathrm{K}$ - trkB isoforms, respectively. $b$, Schematics of $\mathrm{K}^{+}$and $\mathrm{K}-\operatorname{trkB}$ isoforms showing extracellular (EC), transmembrane (TM), and kinase (K) domains. The striped bar in the bottom schematic depicts the variable-length juxtamembrane region responsible for the multiple amplification products found for $\mathrm{K}-\operatorname{trkB}$ in $a$. Horizontal lines indicate the trkB products expected for the $\mathrm{K}^{+}(713 \mathrm{bp})$ and largest $\mathrm{K}-(\approx 600 \mathrm{bp})$ trkB isoforms. C, Hpall digestion $(+)$ of $\mathrm{CG}$ and DRG $\mathrm{K}^{+}$trkB amplification products (site marked by * in $b$ ) yielded restriction fragments of identical and predicted sizes (499 and 214 bp). Undigested $\mathrm{K}^{+}$trkB (-). Lane markers in $a$ and c depict a 100 bp DNA ladder (200-1000 bp).
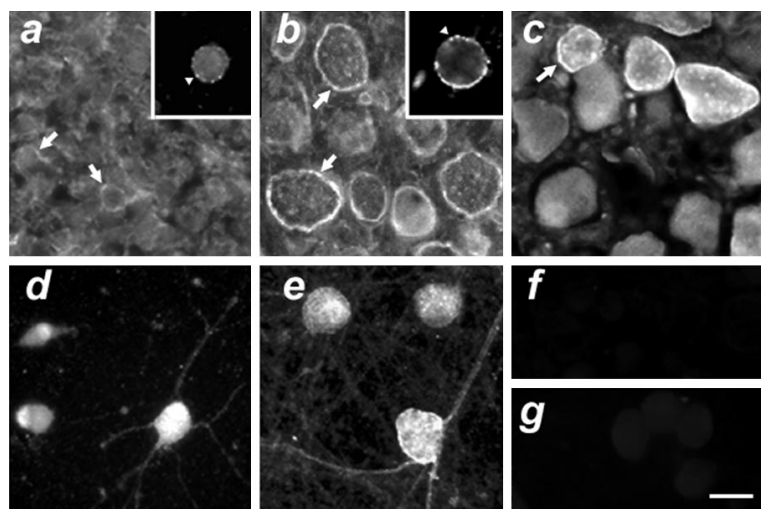

Figure 2. Localization of trkB protein to ciliary ganglion neurons. $a-c$, Ganglion sections obtained from E8 CG, E14 CG, and E15 DRG, displayed neuronal immunoreactivity after labeling with primary antiserum recognizing an extracellular epitope of chicken trkB. Both intracellular and cell-surface trkB labeling (arrows) was evident. Insets in $a$ and $b$ show freshly dissociated E8 and E14 (G neurons displaying punctate cell-surface trkB labeling (arrowheads). $d, e$, trkB labeling of E8 CG neuron somata and processes after $8 \mathrm{hr}(d)$ and on day $4(\mathrm{~d} 4)$ in culture $(e) . f$, $g$, To demonstrate specificity, E14 CG sections ( $f$ ) and d4 C G cultures $(g)$ processed without the trkB primary antiserum were unlabeled, as were E8 CG, E15 DRG, acutely dissociated CG neurons, and $8 \mathrm{hr}$ (G cultures (data not shown). Scale bar: (in $g$ ), $a-g, 20 \mu \mathrm{m}$.

the two developmental ages. In CG neuron cultures, the somata and processes of neurons displayed specific trkB labeling that became more extensive and intense between $8 \mathrm{hr}$ and $4 \mathrm{~d}$ in culture (Fig. 2d,e,g), a period when functional synapses are formed and increase in activity (Chen et al., 2001). At $4 \mathrm{~d}$ in culture, $\sim 80 \%$ of CG neurons scored positive for trkB immunoreactivity. These findings demonstrate that trkB protein is ex-

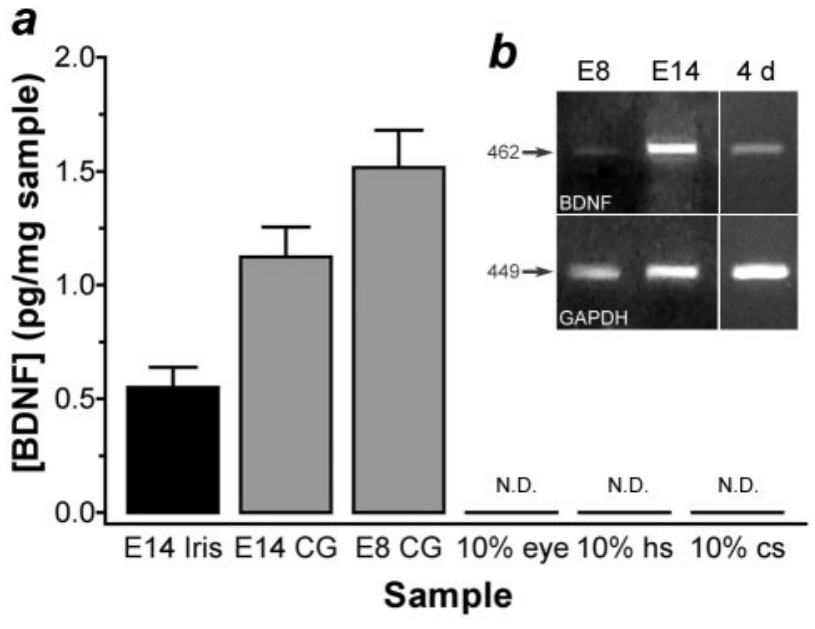

Figure 3. Detection of BDNF protein and mRNA. $a$, ELISAs demonstrate the presence of BDNF-like protein in tissue homogenates prepared from a ciliary neuron target, the iris constrictor muscle (Iris, black bar), as well as from E8 and E14 CG (gray bars). BDNF was not present at detectable levels (ND) in 10\% eye extract (10\% eye), 10\% heat inactivated horse serum (10\% hs), or $10 \%$ chicken serum ( $10 \%$ cs). b, PCR primers specific for chicken BDNF (top row) amplified products consistent with the expected size of $462 \mathrm{bp}$ (arrow) from cDNA derived from E8 and E14 CG, and in separate experiments from E8 CG neurons after $4 \mathrm{~d}$ growth in culture. GAPDH amplifications (bottom row, $449 \mathrm{bp}$ ) were performed as positive controls in parallel reactions from paired experiments.

pressed by CG neurons and, because dissociated neurons in acute and culture preparations were not permeabilized, indicate that a substantial fraction is localized on the cell surface. Taken together, the mRNA and protein studies further suggest that catalytically competent, high-affinity BDNF receptors are present in the ganglion and that their expression on CG neurons increases during periods of synaptic differentiation both in vivo and in cell culture.

\section{Functional relevance of BDNF and trkB}

To be relevant in vivo, endogenous BDNF should both be present in the CG and be able to elicit trk-dependent signaling in the neurons. Because BDNF detected in spinal cord ventral horn results from both local synthesis and retrograde transport to motor neurons from striated muscle (Koliastsos et al., 1993), we tested for the presence of BDNF both in CG and in the iris, a ciliary neuron target that like the ciliary body is primarily striated muscle in birds (Marwitt et al., 1971). Using a commercial ELISA, we detected BDNF-like protein in E14 iris muscle as well as in E14 and in E8 CG (Fig. 3a). The assay failed to detect BDNF in 10\% heat inactivated horse serum or whole eye extract, routinely used at 10 and $3 \%$, respectively, as supplements to CG culture medium. The assay also failed to detect BDNF-like protein in intact chicken serum. Relevant to our culture experiments, we presume that dilution of BDNF derived from the iris and ciliary muscle during eye extract preparation reduces its concentration below the detection limit of the assay $(7.8 \mathrm{pg} / \mathrm{ml})$. BDNF-like protein present in E8 and E14 CG may be the source of the strong BDNF immunoreactivity previously reported at the same developmental ages for accessory oculomotor neurons (Steljes et al., 1999) which provide preganglionic input to the CG. In addition to arriving by retrograde transport from the intraocular muscle targets, however, the BDNF-like protein present in the CG may also result from local synthesis, because BDNF mRNA was detectable by RT-PCR in E8 and E14 ganglia and in CG neurons maintained in standard culture medium for $4 \mathrm{~d}$ (Fig. $3 b$ ). 

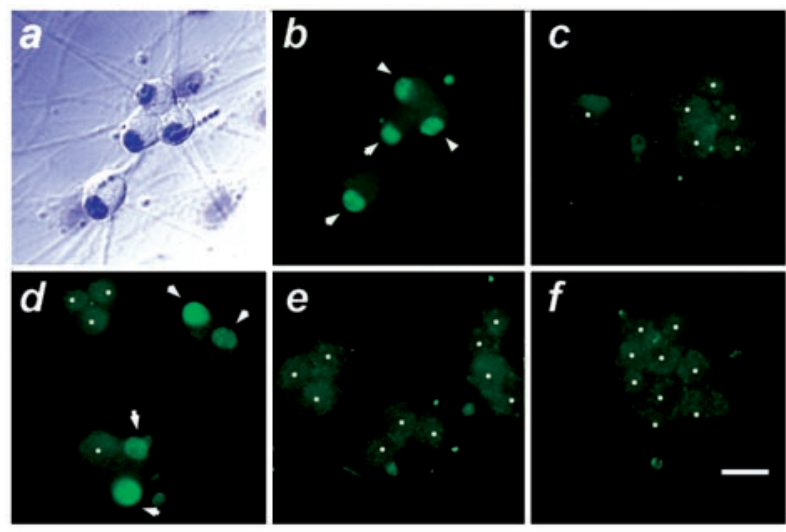

g
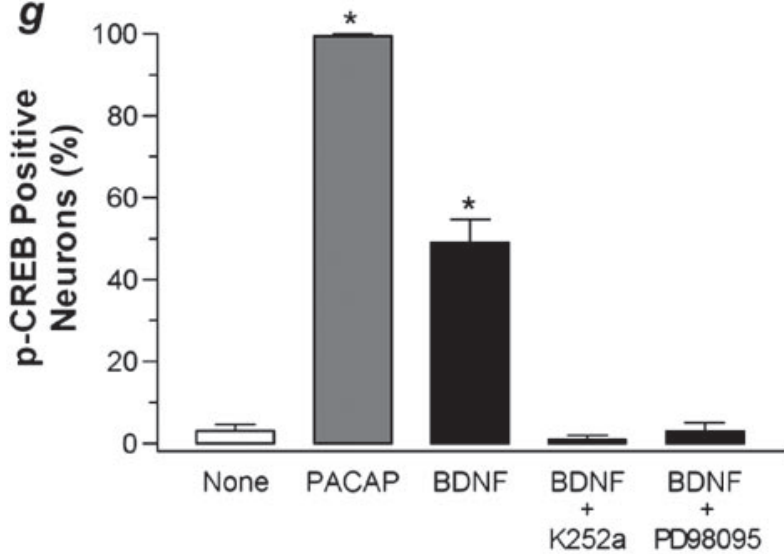

Treatment

Figure 4. BDNF induction of CREB phosphorylation indicates trkB receptors on CG neurons are functional. $a-c$, Nearly all CG neuron nuclei (labeled by DAPI staining in $a$ ) displayed detectable $p$-CREB immunoreactivity after treatment with $100 \mathrm{~nm} \operatorname{PACAP}(b)$, whereas $p$-CREBimmunoreactive neuronal nuclei were virtually absent in untreated cultures $(c) . d-f$, After incubation with BDNF, many neuron nuclei displayed detectable $p$-CREB immunoreactivity (d), which was absent in cultures cotreated with $100 \mathrm{ng} / \mathrm{ml} \mathrm{BDNF}$ and $200 \mathrm{~nm} \mathrm{K252a}(e)$ or $50 \mu \mathrm{m}$ PD98059 ( $f$ ). Scale bar: (in $f$ ), $a-f, 20 \mu \mathrm{m}$. Arrowheads and dots mark neuronal nuclei scoring as p-CREB-positive and -negative, respectively. g, Summary of treatment results. Bars represent the mean percentage of neurons per field with $p$-CREB-immunoreactive nuclei after the indicated treatments ( $N=85-321$ neurons in $6-18$ fields from 2 experiments). Asterisks indicate a significant difference ( $p<0.001$, unpaired $t$ test) from untreated cultures tested in parallel.

To determine if the trkB protein expressed on CG neurons represents functional receptor, we tested the ability of applied BDNF to cause phosphorylation of CREB, a cAMP- and $\mathrm{Ca}^{2+}$ regulated transcription factor (for review, see Impey et al., 1996; Greenberg and Ziff, 2001; Deisseroth et al., 2003), whose activation is a hallmark of trk-dependent neurotrophin signaling (Finkbeiner et al., 1997) (Fig. 4). For this purpose, CG neurons grown in culture for $4-5 \mathrm{~d}$ were challenged with BDNF (100-200 $\mathrm{ng} / \mathrm{ml} ; 10-15 \mathrm{~min}$ ) or, as a positive control, with pituitary adenylate cyclase activating polypeptide (PACAP; $100 \mathrm{nM}, 10-15$ $\mathrm{min}$ ), previously shown to cause robust increases in intracellular cAMP and $\mathrm{Ca}^{2+}$ (Margiotta and Pardi, 1995; Pardi and Margiotta, 1999), and then tested the cultures for p-CREB immunoreactivity. A similar immunocytochemical approach was previously shown to provide a convenient all-or-none assay for CREB activation in single hippocampal neurons (Hu et al., 2002). After treatment with BDNF, $49 \pm 6 \%$ of 321 CG neurons from 18 fields $(N=321,18)$ scored as p-CREB-positive, compared with $99 \pm$ $2 \%(N=132,9)$ after PACAP treatment and $3 \pm 2 \%(N=179$, 10) in untreated control cultures assayed in parallel (Fig. $4 a-d, g$ ).
Consistent with a requirement for trkB signaling, the proportion of p-CREB positive neurons induced by BDNF dropped to control levels $(1 \pm 1 \% ; N=114,6)$ after $1 \mathrm{hr}$ preincubation and 15 min cotreatment with K252a (Fig. 4e,g), a trk-selective tyrosine kinase inhibitor (Pizzorusso et al., 2000). Preincubation (1 hr) and 15 min cotreatment with PD98059, an MEK1 inhibitor that blocks the neurotrophin-activated, RAS-dependent signaling pathway leading to CREB activation (Ying et al., 2002) similarly reduced the proportion of $\mathrm{p}$-CREB positive neurons induced by BDNF to $3 \pm 2 \%(N=85,6)$ (Fig. $4 f, g)$. The observation that $51 \%$ of neurons showed no detectable response to BDNF in this assay cannot be explained by limited CREB availability because nearly all nuclei were immunoreactive after PACAP treatment. The difference might instead reflect suboptimal BDNF treatment times or heterogeneity of functional trkB expression levels. In either case, the protein and p-CREB assays (Figs. 3, 4) demonstrate that an endogenous source of BDNF-like protein is present in the parasympathetic CG, where it is poised to activate functionally competent trkB receptors present on the neurons and thereby recruit appropriate signal pathways leading to CREB activation.

\section{BDNF upregulates $\alpha 7$-nAChRs}

Because neurotrophins are not required for full survival of CG neurons, we examined possible roles for BDNF-trkB signaling in regulating the components and function of nicotinic synapses on the neurons. $\alpha 7$-nAChRs were assessed as potential targets of BDNF-trkB signaling because they can rapidly modulate transmission (McGehee et al., 1995; Gray et al., 1996; Wonnacott, 1997; Margiotta and Pugh, 2004), an action resembling the increased synaptic efficacy produced by BDNF (for review, see McAllister et al., 1999; Schnider and Poo, 2000; Poo, 2001). $\alpha$-Bgt binds with high affinity to $\alpha 7$-nAChRs (Couturier et al., 1990b) and $\left[{ }^{125} \mathrm{I}\right] \alpha$-Bgt was therefore used to quantify surface $\alpha 7$ nAChRs on CG neurons (Fig. 5a), as previously described (McNerney et al., 2000). In CG neuron cultures grown with BDNF for varying times before assay at $5 \mathrm{~d},\left[{ }^{125} \mathrm{I}\right]-\alpha$-Bgt binding was unchanged relative to control cultures after $4 \mathrm{hr}$ exposure, but increased nominally (24\%) after $16 \mathrm{hr}$. Extending the treatment time to the full $5 \mathrm{~d}$ culture period resulted in levels of $\alpha$-Bgt binding that were significantly higher $(62 \pm 10 \%$; $p<0.01)$ in CG cultures exposed to BDNF relative to control cultures assayed in parallel ( $N=10$ for both). Actual levels of $\left[{ }^{125} \mathrm{I}\right]-\alpha$-Bgt bound in control cultures and cultures treated with BDNF for $5 \mathrm{~d}$ were $3.9 \pm 0.2$ and $6.0 \pm 0.4 \mathrm{fmol} / \mathrm{CG}$ equivalent, respectively. In principle, the increased levels of $\alpha 7$-nAChRs seen after exposure to BDNF could have been caused by activation of either trkB or the low-affinity neurotrophin receptor $\left(\mathrm{p} 75^{\mathrm{NTR}}\right)$ that is also present on CG neurons (Lee et al., 2002). The latter possibility is unlikely, however, because an identical elevation $(62 \pm 14 \% ; N=$ 3) was observed when BDNF was coapplied for $5 \mathrm{~d}$ with ChEX, a $\mathrm{pAb}$ that recognizes and blocks chicken $\mathrm{p} 75^{\mathrm{NTR}}$ but not trk function (Wescamp and Reichardt, 1991). The ability of long-term BDNF exposure to upregulate $\alpha 7$-nAChRs may reflect increased $\alpha 7$-nAChR subunit gene expression because levels of $\alpha 7$-nAChR subunit relative to $\beta \mathrm{A}$ mRNA, determined by semiquantitative RT-PCR, were elevated significantly (by $53 \pm 10 \%$ ) in cultures treated with BDNF for $4-5 \mathrm{~d}$ compared with untreated control cultures, tested in parallel ( $N=6$ each) (Fig. $5 b)$. As with the protein assays, BDNF also increased $\alpha 7$-nAChR subunit mRNA in cultures with $\mathrm{p} 75^{\mathrm{NTR}}$ blocked by coapplication with ChEX $(41 \pm 15 \% ; N=3)$. Using real-time PCR, a $98 \pm 26 \%(N=5)$ increase in $\alpha 7$-nAChR subunit relative to GAPDH mRNA was 


\section{a $\alpha$ Bgt Binding}

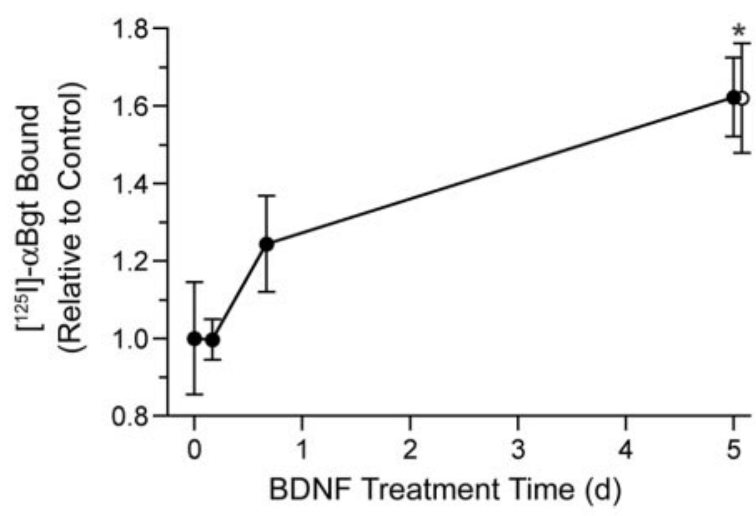

\section{b Gel-Based PCR}

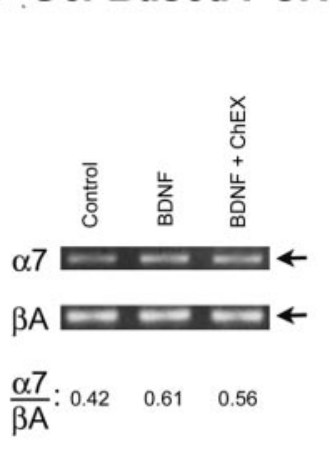

\section{c Real-Time PCR}

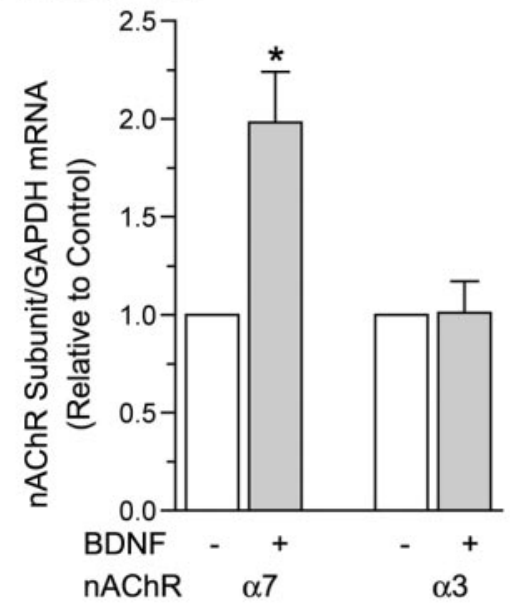

Figure 5. BDNF increases $\alpha 7-\mathrm{nAChR}$ surface sites and $\alpha 7-\mathrm{nAChR}$ subunit mRNA. $a, \alpha 7-$ $\mathrm{nAChR}$ levels were determined by quantifying [ $\left.{ }^{125} \mathrm{I}\right]$ - $\alpha$-Bgt surface binding sites in CG neuron cultures maintained for $5 \mathrm{~d}$. Data points indicate mean ( \pm SEM) femtomoles of [ $\left.{ }^{125} \mathrm{I}\right]-\alpha$-Bgt bound per ganglion equivalent relative to control cultures after exposure to BDNF for $0 \mathrm{hr}$ ( $N=$ 12 ), $4 \mathrm{hr}$ (from day $5 ; N=3$ ), $16 \mathrm{hr}$ (from day $4 ; N=6$ ), or $5 \mathrm{~d}$ (from day $0 ; N=10$ ). The open circle depicts relative $\left[{ }^{125} \mathrm{I}\right]-\alpha$-Bgt binding levels for cultures treated with both BDNF and ChEX $(N=3)$. Asterisk indicates a significant increase in $\left[{ }^{125} \mathrm{l}\right]-\alpha$-Bgt binding after $5 \mathrm{~d}$ exposure compared with untreated control cultures from the same platings $(p<0.05)$ and applies to BDNF incubations with and without ChEX. $b$, Separate PCR amplifications were conducted on cDNAs isolated from control or BDNF-treated ( $4-5 d$ ) C neuron cultures (with or without ChEX) on $\mathrm{d} 4$ or $\mathrm{d} 5$ using primer pairs specific for the indicated chicken $\mathrm{nAChR}$ subunit or $\beta A$. $b$, Left, observed (Fig. $5 c$ ). In both cases, the BDNF-induced increases in $\alpha 7$-nAChR subunit mRNA were selective in the sense that identical treatments failed to significantly alter $\alpha 3-\mathrm{nAChR}$ subunit mRNA levels (Fig. 5b,c).

Having demonstrated that BDNF induces trk-dependent increases in levels of $\alpha 7$-nAChR protein and mRNA in CG neurons, we next sought to determine if the same treatments also enhanced $\alpha 7$-nAChR-mediated currents. Rapid application of nicotine (Nic; $20 \mu \mathrm{M})$ to CG neurons grown in culture typically induces a whole-cell current response featuring an initial fast-desensitizing component that is blocked by $\alpha$-Bgt (Fig. 6a) and hence mediated by $\alpha 7$-nAChRs (Pardi and Margiotta, 1999; McNerney et al., 2000; Nai et al., 2003). Whereas $65 \pm 5 \%(N=80$ neurons; 5 platings) of CG neurons grown in standard culture medium displayed rapidly decaying, $\alpha 7$-nAChR-mediated currents, BDNF treatment for 3-4 d increased the proportion to $83 \pm 4 \%(N=$ $76,5)$. In such cases, the peak $\alpha 7$-nAChR current values relative to membrane capacitance $\left(I_{\text {fast }} / C_{\mathrm{m}}, \mathrm{pA} / \mathrm{pF}\right)$ were $49 \pm 14 \%(N=$ $63,5)$ larger for neurons from cultures treated with BDNF compared with untreated controls $(N=52,5)$ tested in parallel (Fig. $6 b, c)$. Consistent with the time course for upregulation of surface $\alpha 7$-nAChRs seen in the $\left[{ }^{125} \mathrm{I}\right]-\alpha$-Bgt binding studies, BDNF treatments for 10-30 min or 16-24 hr produced only nominal increase in $I_{\text {fast }} / C_{\mathrm{m}}$ relative to untreated controls tested in parallel (Fig. 6b) (data not shown, $p>0.05$ for both). The slowly decaying component of the Nic-induced current is mediated primarily by heteromeric $\alpha 3^{\star}$-nAChRs (Nai et al., 2003) that contain $\alpha 3, \alpha 5$, $\beta 4$, and occasionally $\beta 2$ subunits, but lack $\alpha 7$ subunits (Vernallis et al., 1993; Conroy and Berg, 1995) and are insensitive to $\alpha$-Bgt (Fig. 6a). The ability of BDNF to increase $I_{\text {fast }} / C_{\mathrm{m}}$ was specific for $\alpha 7$-nAChRs because slow currents $\left(I_{\text {slow }} / C_{\mathrm{m}}\right)$ attributable to $\alpha 3^{*}$ $n A C h R s$ and present in all neurons, were unchanged after exposure to BDNF for 10-30 min, 16-24 hr, or 4-5 d (Fig. 6b). In addition, the 4-5 d BDNF treatments had no discernible effects on membrane capacitance or the voltage sensitivity or maximal values of voltage-activated $\mathrm{Na}^{+}$or $\mathrm{Ca}^{2+}$ currents (data not shown). In summary, the size, latency, and specificity of the increased $\alpha 7$-nAChR current responses seen after chronic BDNF treatment are consistent with the BDNF-activated trkBdependent upregulation of $\alpha 7-\mathrm{nAChR}$ mRNA and protein that occur over a similar time course.

\section{BDNF increases activity at nicotinic synapses}

Functional synapses form between CG neurons in culture (Margiotta and Berg, 1982) and display spontaneous, impulse-driven

The resulting products were separated by gel electrophoresis and had sizes appropriate for $\beta A$ (275 bp), $\alpha 7$-nAChR subunit (522 bp) (arrows), and $\alpha 3$-nAChR subunit (252 bp, data not shown). In the example, note that the intensity of $\alpha 7$-nAChR subunit relative to $\beta$ A product was higher for BDNF-treated cultures (with or without ChEX) than for controls. b, Right, Summary of mean ( \pm SEM) relative $\alpha 7$-nAChR and $\alpha 3$-nAChR subunit product fluorescence intensity under different treatment conditions. In this gel-based assay, the relative levels of $\alpha 7$ nAChR subunit mRNA were $53 \pm 10 \%$ higher in BDNF-treated (black bar) compared with control cultures (white bar) within the same experiments $\left({ }^{*} p<0.01 ; N=6\right.$; paired $t$ test), and a similar increase $(41 \pm 15 \%)$ persisted when BDNF was applied in the presence of CHEX (hatched bar) to block p $75^{\mathrm{NTR}}(p<0.05 ; N=3)$. In contrast, the BDNF treatments failed to significantly change mRNA levels for $\alpha 3$-nAChR subunit ( $p>0.05 ; N=5$ ). c, For confirmation, real-time $P C R$ amplifications were conducted on CDNAs isolated from control or BDNF-treated (4-5 d) CG neuron cultures using primer pairs specific for the indicated chicken nAChR subunit or GAPDH. Using this approach, the levels of $\alpha 7$-nAChR subunit mRNA were $98 \pm 26 \%$ higher in BDNF-treated (gray bar) compared with control cultures (white bar) ${ }^{*} p<0.02 ; N=$ 5; unpaired $t$ test), whereas mRNA levels for $\alpha 3$-nAChR subunit were unchanged ( $p>0.1$; $N=4)$. 
nicotinic EPSCs (sEPSCs) (Fig. 7). We previously demonstrated that although $\alpha 7$ nAChRs contribute to the sEPSCs, the vast majority require $\alpha 3^{*}$-AChRs because $\alpha$-Conotoxin-MII, which blocks $\alpha 3^{*}$ - but not $\alpha 7$-nAChRs on CG neurons (Nai et al., 2003) reduced sEPSC frequency by $95 \%$ (Chen et al., 2001). Exposure to BDNF substantially increased the overall frequency of sEPSCs (Fig. 7), most of which display slow decay kinetics indicative of a major contribution from $\alpha 3^{\star}$-nAChRs (Chen et al., 2001). After 16-24 hr BDNF treatment, sEPSC frequency increased approximately threefold $(2.69 \pm 0.35 ; N=$ 46) relative to untreated control neurons from the same five cultures tested in parallel $(1.00 \pm 0.17 ; N=39)$, with a smaller yet significant increase seen after $4-5 \mathrm{~d}$ treatment (Fig. 7A,B). This effect is reminiscent of that seen at other synapses, where BDNF increases EPSC frequency by a presumed presynaptic mechanism (McAllister et al., 1999; Schnider and Poo, 2000; Poo, 2001) (see below). To determine if BDNF also altered sEPSC amplitudes, well separated individual synaptic currents were extracted from selected records, and components mediated by $\alpha 7$ -

and $\alpha 3^{*}$-nAChRs were identified by their diagnostic fast and slow decay kinetics, as previously described (Chen et al., 2001). The amplitudes of fast, $\alpha 7$-nAChR-mediated sEPSCs identified in this manner increased after 16-24 hr of BDNF treatment (Fig. $7 D$ ), shifting by $32 \%$ from a median value of $-9.6 \mathrm{pA}$ in controls to $-12.7 \mathrm{pA}$ in BDNF-treated cultures ( $N=4$ neurons each; $p<$ 0.0004; Mann-Whitney $U$ and Kolmogorov-Smirnov tests). The effect was selective for $\alpha 7$-nAChR-mediated sEPSCs because, despite increasing in frequency, slow $\alpha 3^{*}$-nAChR-mediated sEPSCs displayed amplitudes that were unchanged by BDNF treatment (Fig. $7 E)$. Recent studies indicate that chronic exposure to BDNF increases the proportion of postsynaptic $\alpha 7$-nAChR clusters on hippocampal neurons (Kawai et al., 2002). Because $\alpha 3^{*}$-nAChR mediated sEPSC amplitudes were unchanged, a similar postsynaptic accumulation of $\alpha 7$-nAChRs may also explain the larger amplitude fast sEPSCs seen here after 16-24 hr exposure to BDNF.

Although significant and $\alpha 7$-nAChR-selective, the changes in fast sEPSC amplitudes after 16-24 hr BDNF treatment were small in comparison to the accompanying threefold increase in the frequency of (primarily) $\alpha 3^{*}$-nAChR-mediated sEPSCs. Studies in other systems suggest that this latter, more dramatic effect is likely to be presynaptic in origin, possibly resulting from changes in intracellular $\mathrm{Ca}^{2+}$ dynamics that alter quantal release (Pozzo-Miller et al., 1999; Tyler et al., 2002). Interestingly, presynaptic $\alpha 7$-nAChRs enhance neurotransmitter release and are known to do so by elevating terminal $\mathrm{Ca}^{2+}$ levels (Gray et al., 1996; Coggan et al., 1997), possibly through $\mathrm{Ca}^{2+}$-induced $\mathrm{Ca}^{2+}$-release (CICR) recently shown to increase EPSC frequency (Sharma and Vijayaraghavan, 2003). Because CG neurons in culture express $\mathrm{Ca}^{2+}$-permeable $\alpha 7$-nAChRs on neurite tips (Pugh and Berg, 1994), and activation of CICR markedly enhances sEPSC frequency (M. Chen and J. Margiotta, unpublished observations), we wondered if upregulation of presynaptic $\alpha 7$ nAChRs might underlie the ability of BDNF to increase sEPSC
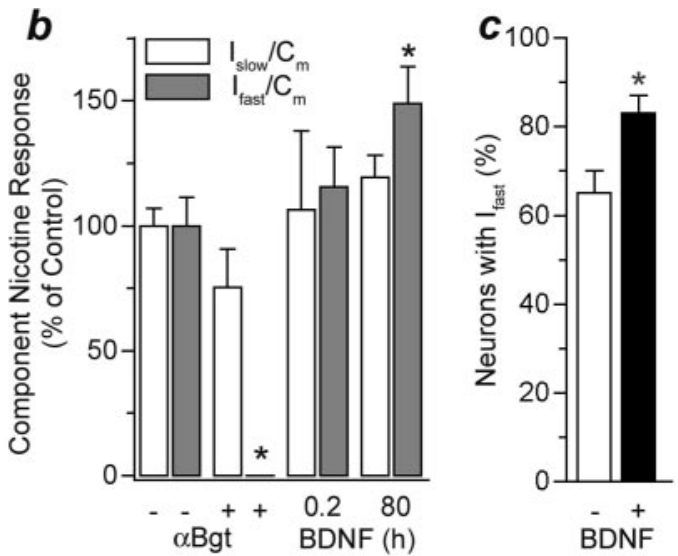

Figure 6. BDNF enhances $\alpha 7-n A C h R$ currents. CG neurons were held at $-70 \mathrm{mV}$, and whole-cell nAChR currents were induced by pressure microperfusion with $20 \mu \mathrm{m}$ Nicotine ( $2 \mathrm{sec}, 10-15 \mathrm{psi}$ ). $a$, Example records showing that $\alpha 7$-AChRs mediate the initial (t)

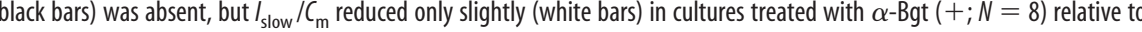
proportion of neurons with detectable $I_{\text {fast }}$ from $65 \pm 5 \%(N=80)$ in control cultures to $83 \pm 4 \%(N=76)$ in treated cultures. Asterisks indicate a significant difference from untreated controls tested in parallel $(p<0.05)$.

frequency. This hypothesis predicts that BDNF applied for 10-30 min should not increase sEPSC frequency because brief exposures were insufficient to increase surface $\alpha 7$-nAChR levels or somatic $\alpha 7$-nAChR currents (Figs. 5, 6). In accord with results from other systems (McAllister et al., 1999; Schnider and Poo, 2000; Poo, 2001) however, brief exposure to BDNF induced a significant, K252a-sensitive increase in sEPSC frequency (Fig. 7C, left), thereby demonstrating an expected trk dependence, but arguing against a requirement for rapid $\alpha 7$-nAChR modulation. Because $\alpha 7$-nAChRs at somatic and presynaptic sites could differ in their acute responsiveness to BDNF, we devised a more direct test, blocking $\alpha 7$-nAChRs with $\alpha$-Bgt and comparing sEPSCs in cultures treated with or without coapplied BDNF. Even with $\alpha$-Bgt present to block $\alpha 7$-nAChRs, however, BDNF applied for 16-24 hr was still able to increase sEPSC frequency (Fig. 7C, right), with all events now displaying slow decay kinetics indicative of $\alpha 3^{*}$-nAChRs. These results indicate that brief- $(10-30$ $\mathrm{min})$ and intermediate-duration exposures to BDNF (16-24 hr) can increase sEPSC frequency and do so without a requirement for $\alpha 7$-nAChRs. Nevertheless, $\alpha 7$-nAChRs are strongly implicated in long-term synaptic regulation (Role and Berg, 1996; MacDermott et al., 1999; Liu et al., 2001; Kawai et al., 2002). Thus, because $4-5 \mathrm{~d}$ BDNF treatments also increased sEPSC frequency and were required to detect significant changes in $\alpha 7$ nAChRs, we cannot exclude the possibility that chronic neurotrophin exposure sustains the long-term function of neuronal nicotinic synapses in ways that somehow depend on $\alpha 7$-nAChRs.

\section{Discussion}

\section{Detection of trkB and BDNF}

We have shown that trkB and BDNF-like proteins are present in the chick CG, a model parasympathetic system, where both trks and neurotrophins were presumed irrelevant. No other studies have attempted to detect trkB protein in CG, however, previous Northern and RNase protection analyses failed to detect trkB 
A
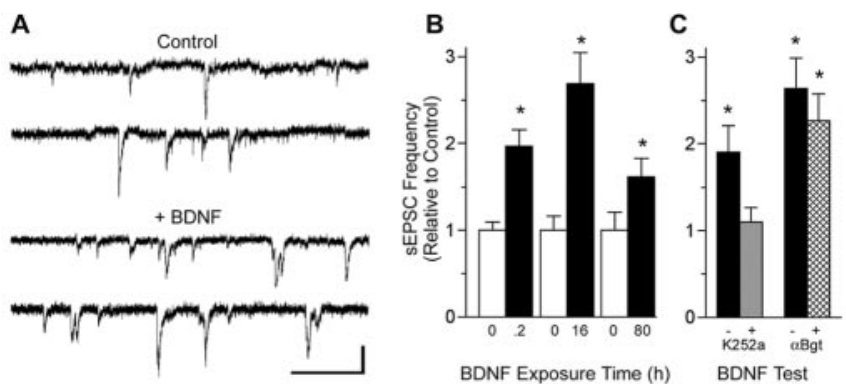

D

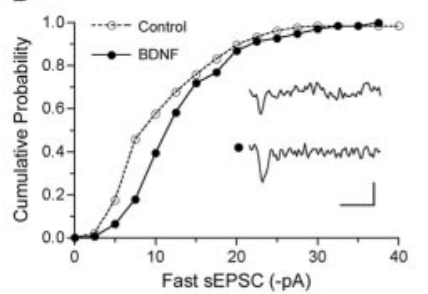

E

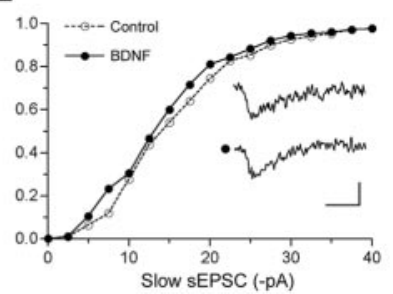

Figure 7. BDNF enhances function at nicotinic synapses. $A$, Example records of $s E P S C s$ obtained on day 5 from control and BDNF-treated ( $16 \mathrm{hr}, 50 \mathrm{ng} / \mathrm{ml}$ BDNF) CG neurons from the same cultures. Calibration: 25 pA, 100 msec. B, BDNF treatment effects on sEPSC frequency. Values indicate mean ( \pm SEM) SEPSC frequency in neurons assessed on day 4 or day 5 after exposure to BDNF (black bars) for $10-30 \mathrm{~min}(0.2 \mathrm{hr} ; N=71), 16-24 \mathrm{hr}(16 \mathrm{hr} ; N=46)$, or $4-5 \mathrm{~d}(80 \mathrm{hr} ; N=29)$ relative to that for control neurons not exposed to BDNF (white bars; $N=$ $74,37,21$, respectively) tested in parallel. C. Tests for trk and $\alpha 7-n A C h R$ involvement in BDNFenhanced synaptic function. The ability of BDNF to increase sEPSC frequency (black bars) is abolished by 10-30 min coincubation with $200 \mathrm{~nm} \mathrm{K252a}$ to block trks (gray bar, left) but unaffected by $16-24 \mathrm{hr}$ coincubation with $\alpha$-Bgt to block $\alpha 7$-nAChRs (hatched bar, right). In both $B$ and $C$, asterisks indicate a significant increase sEPSC frequency for the indicated conditions compared with untreated control cultures from the same platings ( $p<0.05$ ). $D, E$, Summary of BDNF treatment effects on $\alpha 7$ - and $\alpha 3^{*}$-nAChR-mediated SEPSC amplitudes. Cumulative amplitude distribution histograms are shown for fast-decaying sEPSC $s$ mediated by $\alpha 7$-nAChRs (D) and slow-decaying sEPSCs mediated by $\alpha 3^{*}$-nAChRs $(E)$ in control neurons (open circles) and in neurons treated with $50 \mathrm{ng} / \mathrm{ml}$ BDNF for $16-24 \mathrm{hr}$ (filled circles). BDNF treatment resulted in a significant shift in fast sEPSC amplitudes $(D)$ from a median of $-9.6 \mathrm{pA}$ $(N=137)$ for control neurons to $-12.7 \mathrm{pA}(N=139)$ for BDNF-treated neurons $(p<0.0004$; Mann-Whitney $U$ and Kolmogorov-Smirnov tests). In contrast, slow sEPSC amplitudes $(E)$ were unaffected by the treatment, with median amplitudes of $-15.0 \mathrm{pA}(\mathrm{N}=220)$ and -14.5 $\mathrm{pA}(N=180)$ for control and BDNF-treated neurons, respectively ( $p>0.06$, same tests). Insets show examples of fast and slow SEPSCs with amplitudes close to the median values for control (top) and BDNF treatment (bottom, with dot) conditions. Calibration: 10 pA, 2 msec.

mRNA (Dechant et al., 1993; Hallbook et al., 1995), possibly because of the lower sensitivity of these assays compared with RT-PCR. Standard criteria for trkB primer (Garner and Large, 1994; Garner et al., 1996) and antiserum specificity (von Bartheld et al., 1996), as well as controls involving primer and primary antiserum omission (this study) support our detection of trkB mRNA in CG, and cell surface trkB protein on CG neurons. In addition, the observations that BDNF elicits trk-dependent signaling leading to CREB activation and trk-dependent changes in $\alpha 7$-nAChRs and synaptic function further indicate that CG neurons express functional trkB. Because the trkB antiserum used recognizes an extracellular epitope (von Bartheld et al., 1996), and PCR amplifications using $F / R_{\mathrm{K}}$ primers revealed the presence of isoforms lacking an intracellular kinase domain, however, some trkB immunoreactivity may represent truncated receptor. Whereas the role of kinase-deficient trk isoforms is poorly understood, the notion they are expressed on CG neurons is strengthened by the observation that in $50 \%$ of neurons BDNF application failed to induce $\mathrm{p}-\mathrm{CREB}$, a process expected to require trkB kinase activity (Finkbeiner et al., 1997; Huang and Reichardt,

2003). In such cases, full-length trkB receptors may still be present but either rendered functionally incompetent or expressed at levels insufficient to activate CREB because truncated trk isoforms have been reported to inhibit both the function and expression of full-length receptors (for review, see Huang and Reichardt, 2003).

\section{BNDF-trkB signaling upregulates $\alpha$-nAChRs}

BDNF treatment for $4-5 \mathrm{~d}$ induced trk-dependent increases in $\alpha 7$ subunit mRNA and surface $\alpha 7$-nAChRs, and enhanced $\alpha 7$ nAChR-mediated whole-cell currents, all without changing levels of $\alpha 3$ subunit mRNA or $\alpha 3^{\star}$-nAChR-mediated currents. Similarly, NGF has been shown to selectively increase expression of $\alpha 7$ - over $\alpha 3$-nAChR subunit mRNA in sympathetic neuron-like PC12 cells (Takahashi et al., 1999; but see Henderson et al., 1994). Although alterations in receptor turnover rates and mRNA stability may contribute, a straightforward interpretation of our results is that BDNF activation of trkB leads to increased $\alpha 7$ $\mathrm{nAChR}$ subunit transcription and protein synthesis, thereby increasing levels of assembled cell-surface receptor. One way BD$\mathrm{NF}-$ trkB signaling may influence $\alpha 7$-nAChR subunit transcription is through activation of transcription factors including not only CREB (Finkbeiner et al., 1997), but also AP-1, or NF- $\kappa$ B, which like CREB are reported to be stimulated by BDNF-trkB signaling (Gaiddon et al., 1996; Lipsky et al., 2001). CRE binding sites are present in promoter-containing regions of human and bovine $\alpha 7$-nAChR subunit genes, although in the chicken gene a 1298 bp 5' segment with a basal promoter at -406 to -230 was previously reported to lack a strong consensus CRE binding site (Matter-Sadzinski et al., 1992; Gault et al., 1998). Within this same $5^{\prime}$ region, however, a new search of two transcription factor databases [Transfac (http://www.gene-regulation.com/pub/ databases.html; Heinemeyer et al., 1998) and Matinspector (http://www.genomatix.de/free login.htm)] did reveal a potential ( $)$ strand CRE binding site $\left(\mathrm{T}_{-1060} \mathrm{GACcTAA}_{-1067}\right)$ upstream from the basal promoter. Potential binding sites for AP-1 $\left(\mathrm{T}_{-715} \mathrm{TcACTCAG}_{-708}\right)$ and NF- $\kappa \mathrm{B}\left(\mathrm{G}_{-176} \mathrm{GGGgcTCCC}_{-167}\right)$ were also predicted in the $5^{\prime}$-flanking and basal promoter regions, respectively. These considerations suggest that BDNF-trkB signaling can regulate the chicken $\alpha 7$-nAChR subunit gene via CRE, AP-1, or NF- $\kappa$ B. Without experimental data, however, it is difficult to judge the significance of these transcription factors as direct regulators. Here, it should be noted that binding sites for Egr-1, Sp1, and Sp3, transcription factors not associated with BDNF-trkB signaling, are thought to regulate the activity of the rat $\alpha 7$-nAChR promoter (Nagavarapu et al., 2001).

\section{BNDF increases activity at nicotinic synapses on CG neurons} BDNF increased sEPSC frequency after acute (10-30 min), intermediate $(16-24 \mathrm{hr})$, or long-term $(4-5 \mathrm{~d})$ treatments. The increased sEPSC frequency after acute BDNF exposure depended on $\operatorname{trkB}$ activation and resembled that seen at other peripheral and central synapses, where enhanced transmitter release from presynaptic terminals is implicated (McAllister et al., 1999; Schnider and Poo, 2000; Poo, 2001). The basis of the acute synaptic effects seen here and in these other systems is unknown, but seems likely to reflect BDNF actions on $\mathrm{Ca}^{2+}$ (Berninger et al., 1993; Stoop and Poo, 1996; Li et al., 1998) and vesicular dynamics (Pozzo-Miller et al., 1999; Tyler et al., 2002) in presynaptic terminals that enhance neurotransmission reliability. The compelling possibility that $\mathrm{Ca}^{2+}$-permeable, presynaptic $\alpha 7$-nAChRs underlie these effects (Gray et al., 1996; Coggan et al., 1997; Sharma and Vijayaraghavan, 2003) is unlikely, however, because 
acute BDNF exposure failed to modulate somatic $\alpha 7-\mathrm{nAChR}$ currents and, more telling, because coincubation with $\alpha$-Bgt failed to block the ability of BDNF to increase sEPSC frequency. Also unlikely are general effects on membrane excitability as seen for PC12 cells (Rudy et al., 1987; Lesser et al., 1997) because BDNF treatments failed to detectably change the amplitude or voltage sensitivity of somatic $\mathrm{Na}^{+}$or $\mathrm{Ca}^{2+}$ currents. In addition to increasing overall sEPSC frequency threefold, 16-24 hr BDNF treatments specifically increased the amplitude of $\alpha 7-\mathrm{nAChR}$ mediated sEPSCs. Although we cannot exclude increased quantal release at presynaptic nerve terminals that contact only $\alpha 7$ nAChR clusters, this effect seems more likely to be postsynaptic in origin. Unlike currents induced by rapid nicotine microperfusion, which represent $\mathrm{nAChR}$ function integrated over the entire soma and report only a nominal increase, sEPSCs are focal events, and an increase in their amplitude would be expected even after adding a few functional receptors in the postsynaptic membrane. The increase in $\alpha 7$-nAChR-mediated sEPSC amplitudes agrees well with the increased postsynaptic $\alpha 7$-nAChR clusters previously observed in hippocampal neuron cultures (Kawai et al., 2002 ) and with the nominal increase in $\left[{ }^{125} \mathrm{I}\right]-\alpha$-Bgt binding seen here after 16-24 hr exposure to BDNF and the significant increase seen after $5 \mathrm{~d}$. The elevated sEPSC amplitude could reflect increased $\alpha 7$-nAChR synthesis, and/or preferential insertion at existing postsynaptic sites, but we cannot presently distinguish between these possibilities.

\section{Long-term synaptic enhancement}

Our findings indicate that acute- and intermediate-term BDNF treatments increased synaptic activity without a requirement for $\alpha 7$-nAChRs. Chronic ( $4-5$ d) BDNF treatments continued to enhance synaptic activity, however, and, in parallel, significantly increased $\alpha 7$-nAChR levels and whole-cell currents. $\alpha 7$-nAChRs have been linked to activity-dependent neurite outgrowth and other developmental processes (for review, see Margiotta and Pugh, 2004) that may normally help ensure appropriate synaptogenesis or sustain existing functional synapses once formed (for review, see Role and Berg, 1996; Broide and Leslie, 1999; Jones et al., 1999). In addition, BDNF has been shown to have potent long-term effects on synaptic development and maintenance in other systems (for review, see Poo, 2001). Thus, although further experiments are needed, it remains possible that, in contrast to short- and intermediate-term $\alpha 7$-nAChR-independent effects, the ability of BDNF signaling to sustain long-term synaptic function is related somehow to coincident regulation of $\alpha 7$-nAChRs.

\section{In vivo relevance?}

Our results do not directly address the relevance of signals generated by BDNF through trkB for CG neurons in vivo. That targets and target-derived factors influence the survival, growth, and differentiation of input neurons, however, has been recognized for decades (Berg, 1984; Levi-Montalcini, 1987). Specific to this report, previous studies demonstrated that synapses on CG neurons undergo patterned maturation between E8 and E18 and that normal neuron survival and ganglionic transmission require connection to the intraocular muscle targets (Landmesser and Pilar, 1974a,b). More recent experiments indicate that $\alpha 7$ subunit mRNA and $\alpha 7$-nAChR protein and currents all increase during the same developmental period (Corriveau and Berg, 1993; Blumenthal et al., 1999) and that severing peripheral target connections reduces levels of $\alpha 7$-mRNA and protein (Brumwell et al., 2002). Given the importance of target connections in sustaining $\alpha 7$-nAChRs and synapses, the presence of BDNF-like protein in the iris target suggests it may influence synaptic properties of CG neurons during development in vivo. The precise spatial and temporal patterns of BDNF and trkB expression still need to be determined. Our PCR and ELISA results suggest, however, that BDNF is both synthesized within the CG, perhaps by the neurons themselves, and transported to the ganglion from the iris muscle. Such local BDNF expression and retrograde transport from the target are consistent with the arrangement in spinal cord (Koliastsos et al., 1993) and would concentrate BDNF in the iris and CG relative to its levels in eye extract, as was observed here. In addition to BDNF, NGF and NT-3 signaling may also be important in the CG system because recent findings indicate $\mathrm{mR}$ NAs for trkA and trkC are expressed in the ganglion, and CG neurons express trkA and trkC immunoreactivity (Dittus et al., 2002). Experiments are in progress to reassess the ability of NGF, NT-3, and BDNF to promote CG neuronal survival, and to identify their respective roles in regulating $\mathrm{nAChR}$ expression and nicotinic synaptic differentiation on these parasympathetic neurons.

\section{References}

Anderson DJ (1999) Lineages and transcription factors in the specification of vertebrate primary sensory neurons. Curr Opin Neurobiol 9:517-524.

Berg DK (1984) New neuronal growth factors. Annu Rev Neurosci 7:149-170.

Berninger B, Garda DE, Inagaki N, Hahnel C, Lindholm D (1993) BDNF and NT-3 induce intracellular $\mathrm{Ca}^{2+}$-elevation in hippocampal neurons. NeuroReport 4:1303-1306.

Blumenthal EM, Shoop RD, Berg DK (1999) Developmental changes in the nicotinic responses of ciliary ganglion neurons. J Neurophysiol 81:111-120.

Broide RS, Leslie FM (1999) The $\alpha 7$ nicotinic receptor in neuronal plasticity. Mol Neurobiol 20:1-16.

Brumwell CL, Johnson JL, Jacob MH (2002) Extrasynaptic a7-nicotinic acetylcholine receptor expression in developing neurons is regulated by inputs, targets, and activity. J Neurosci 22:8101-8109.

Burns AL, Benson D, Howard MJ, Margiotta JF (1997) Chick ciliary ganglion neurons contain transcripts coding for acetylcholine receptorassociated protein at synapses (Rapsyn). J Neurosci 17:5016-5026.

Causing CG, Gloster A, Aloyz R, Bamji SX, Chang E, Fawcett J, Kuchel G, Miller FD (1997) Synaptic innervation density is regulated by neuronderived BDNF. Neuron 18:257-267.

Chen M, Pugh P, Margiotta J (2001) Nicotinic synapses formed between chick ciliary ganglion neurons in culture resemble those present on the neurons in vivo. J Neurobiol 47:265-279.

Coggan JS, Paysan J, Conroy WG, Berg DK (1997) Direct recording of nicotinic responses in presynaptic nerve terminals. J Neurosci 17:5798-5806.

Conroy WG, Berg DK (1995) Neurons can maintain multiple classes of nicotinic acetylcholine receptors distinguished by different subunit compositions. J Biol Chem 270:4424-4431.

Corriveau RA, Berg DK (1993) Coexpression of multiple acetylcholine receptor genes in neurons: quantification of transcripts during development. J Neurosci 13:2662-2671.

Couturier S, Erkman L, Valera S, Rungger D, Bertrand S, Boulter J, Ballivet M, Bertrand D (1990a) $\alpha 5, \alpha 3$, and non- $\alpha 3$ : three clustered avian genes encoding nicotinic acetylcholine receptor-related subunits. JBC 265:17560-17567.

Couturier S, Bertrand D, Matter J-M, Hernandez M-C, Bertrand S, Millar N, Valera S, Barkas T, Ballivet M (1990b) A neuronal nicotinic acetylcholine receptor subunit $(\alpha 7)$ is developmentally regulated and forms a homo-oligomeric channel blocked by $\alpha$-Btx. Neuron 5:847-856.

Dechant G, Biffo S, Okazawa H, Kolbeck R, Pottgiesser J, Barde YA (1993) Expression and binding characteristics of the BDNF receptor chick trkB. Development 119:545-558.

Deisseroth K, Mermelstein PG, Xia H, Tsien RW (2003) Signaling from synapse to nucleus: the logic behind the mechanisms. Curr Opin Neurobiol 13:354-365.

Dichter MA, Fischbach GD (1977) The action potential of chick dorsal root ganglion neurones maintained in cell culture. J Physiol (Lond) 267:281-298.

Dittus JJ, Pugh PC, Howard MJ, Margiotta JF (2002) Parasympathetic ciliary ganglion neurons express trks but neurotrophins fail to fully support their survival. Soc Neurosci Abstr 28:822.7. 
Finkbeiner S, Tavazoie SF, Maloratsky A, Jacobs KM, Harris KM, Greenberg ME (1997) CREB: A major mediator of neuronal neurotrophin responses. Neuron 19:1031-1047.

Finn TP, Kim S, Nishi R (1998) Overexpression of ciliary neurotrophic factor in vivo rescues chick ciliary ganglion neurons from cell death. J Neurobiol 34:283-293.

Gaiddon C, Loeffler JP, Larmet Y (1996) Brain-derived neurotrophic factor stimulates AP-1 and cyclic AMP-responsive element dependent transcriptional activity in central nervous system neurons. J Neurochem 66:2279-2286.

Garner AS, Large TH (1994) Isoforms of the avian TrkC receptor: a novel kinase insertin dissociates transformation and process outgrowth from survival. Neuron 13:457-472.

Garner AS, Menegay HJ, Boeshore KL, Xie X-Y, Voci JM, Johnson JE, Large $\mathrm{TH}$ (1996) Expression of TrkB receptor isoforms in the developing avian visual system. J Neurosci 16:1740-1752.

Gault J, Robinson M, Berger R, Drebing C, Logel J, Hopkins J, Moore T, Jacobs X, Merriwether J, Choi MJ, Kim EJ, Walton K, Buiting K, Davis A, Breese C, Freedman R, Leonard S (1998) Genomic organization and partial duplication of the human $\alpha 7$ neuronal nicotinic acetylcholine receptor gene (CHRNA7). Genomics 52:173-185.

Gonzalez M, Ruggiero FP, Chang Q, Shi YJ, Rich MM, Kraner S, BaliceGordon RJ (1999) Disruption of Trkb-mediated signaling induces disassembly of postsynaptic receptor complexes at neuromuscular junctions. Neuron 24:567-583.

Gray R, Rajan A, Radcliffe K, Yakehiro M, Dani J (1996) Hippocampal synaptic transmission enhanced by low concentrations of nicotine. Nature 383:713-716.

Greenberg ME, Ziff EB (2001) Signal transduction in the postsynaptic neuron. Activity dependent regulation of gene expression. In: Synapses, pp 357-391. Baltimore, MD: Johns Hopkins UP.

Hallbook F, Backstrom A, Kullander K, Kylberg A, Williams R, Ebendal T (1995) Neurotrophins and their receptors in chicken neuronal development. Int J Dev Biol 39:855-868.

Hashino E, Shero M, Junghans D, Rohrer H, Milbrandt J, Johnson EM Jr (2001) GDNF and neurturin are target-derived factors essential for cranial parasympathetic neuron development. Development 128:3773-3782.

Heinemeyer T, Wingender E, Reuter I, Hermjakob H, Kel AE, Kel OV, Ignatieva EV, Ananko EA, Podkolodnaya OA, Kolpakov FA, Podkolony NL, Kolchanov NA (1998) Databases on transcriptional regulation: TRANSFAC, TRRD, and COMPEL. Nucleic Acids Res 26:364-370.

Helfand SL, Smith GA, Wessells NK (1976) Survival and development of dissociated parasympathetic neurons from ciliary ganglia. Dev Biol 50:541-547.

Henderson LP, Gdovin MJ, Liu C, Gardner PD, Maue RA (1994) Nerve growth factor increases nicotinic $\mathrm{ACh}$ receptor gene expression and current density in wild-type and kinase A-deficient PC12 cells. J Neurosci 14:1153-1163.

Hu M, Liu Q-s, Chang KT, Berg DK (2002) Nicotinic regulation of CREB activation in hippocampal neurons by glutamatergic and nonglutamatergic pathways. Mol Cell Neurosci 21:616-625.

Huang EJ, Reichardt LF (2001) Neurotrophins: Roles in neuronal development and function. Annu Rev Neurosci 24:677-736.

Huang EJ, Reichardt LF (2003) Trk receptors: roles in neuronal signal transduction. Annu Rev Biochem 72:609-642.

Impey S, Mark M, Villacres EC, Poser S, Chvkin C, Storm DR (1996) Induction of CRE-mediated gene expression by stimuli that generate longlasting LTP in area CA1 of the hippocampus. Neuron 16:973-982.

Isackson PJ, Towner MD, Huntsman MM (1991) Comparison of mammalian, chicken and Xenopus brain-derived neurotrophic factor coding sequences. FEBS Lett 285:260-264.

Jones S, Sudweeks S, Yakel JL (1999) Nicotinic receptors in the brain: correlating physiology with function. Trends Neurosci 22:555-561.

Kaplan DR, Miller FD (2000) Neurotrophin signal transduction in the nervous system. Curr Opin Neurobiol 10:381-391.

Kawai H, Zago W, Berg DK (2002) Nicotinic alpha 7 receptor clusters on hippocampal GABAergic neurons: regulation by synaptic activity and neurotrophins. J Neurosci 22:7903-7912.

Koliastsos VE, Clatterbuck RE, Winslow JW, Cayouette MH, Price DL (1993) Evidence that brain-derived neurotrophic factor is a trophic factor for motor neurons in vivo. Neuron 10:359-367.

Krieglstein K, Farkas L, Unsicker K (1998) TGF-beta regulates the survival of ciliary ganglionic neurons synergistically with ciliary neurotrophic factor and neurotrophins. J Neurobiol 37:563-572.

Landmesser L, Pilar G (1972) The onset and development of transmission in the chick ciliary ganglion. J Physiol (Lond) 222:691-713.

Landmesser L, Pilar G (1974a) Synaptic transmission and cell death during normal ganglionic development. J Physiol (Lond) 241:737-749.

Landmesser L, Pilar G (1974b) Synapse formation during embryogenesis on ganglion cells lacking a periphery. J Physiol (Lond) 241:715-736.

Lee VM, Sechrist JW, Bronner-Fraser M, Nishi R (2002) Neuronal differentiation from postmitotic precursors in the ciliary ganglion. Dev Biol 252:312-323.

Lesser SS, Sherwood NT, Lo DC (1997) Neurotrophins differentially regulate voltage-gated ion channels. Mol Cell Neurosci 10:173-183.

Leung DW, Parent AS, Cachianes G, Esch F, Coulombe JN, Nickolies D, Eckenstein FP, Nishi R (1992) Cloning, expression during development, and evidence for release o a trophic factor for ciliary ganglion neurons. Neuron 8:1045-1053.

Levi-Montalcini R (1987) The nerve growth factor: thirty-five years later. EMBO J 6:1145-1154.

Lewin GR, Barde YA (1996) Physiology of the neurotrophins. Annu Rev Neurosci 19:289-317.

Li Y-X, Zhang Y, Lester HA, Schuman EM, Davidson N (1998) Enhancement of neurotransmitter release induced by brain-derived neurotrophic factor in cultured hippocampal neurons. J Neurosci 18:10231-10240.

Lindsay RM, Thoenen H, Barde YA (1985) Placode and neural crest-derived sensory neurons are responsive at early developmental stages to brainderived neurotrophic factor. Dev Biol 112:319-328.

Lipsky RH, Xu K, Zhu D, Kelly C, Terhakopian A, Novelli A, Marini AM (2001) Nuclear factor kappaB is a critical determinant in N-methyl-Daspartate receptor mediated neuroprotection. J Neurochem 78:254-264.

Liu Y, Ford B, Mann MA, Fischbach GD (2001) Neuregulins increase $\alpha 7$ nicotinic acetylcholine receptors and enhance excitatory synaptic transmission in GABAergic interneurons of the hippocampus. J Neurosci 21:5660-5669.

Loeb JA, Hmadcha A, Fischbach GD, Land SJ, Zakarian VL (2002) Neuregulin expression at neuromuscular synapses is modulated by synaptic activity and neurotrophic factors. J Neurosci 22:2206-2214.

Lohof AM, Ip NY, Poo M-m (1993) Potentiation of developing neuromuscular synapses by the neurotrophins NT-3 and BDNF. Nature 363:350-353.

MacDermott AB, Role LW, Siegelbaum SA (1999) Presynaptic ionotropic receptors and the control of transmitter release. Annu Rev Neurosci 22:443-485.

Maisonpierre PC, Belluscio L, Conover JC, Yancopoulos GD (1992) Gene sequences of chicken BDNF and NT-3. DNA Seq 3:49-54.

Margiotta JF, Berg DK (1982) Functional synapses are established between ciliary ganglion neurons in dissociated cell culture. Nature 296:152-154.

Margiotta J, Pardi D (1995) Pituitary adenylate cyclase-activating polypeptide type I receptors mediate cyclic AMP-dependent enhancement of neuronal acetylcholine sensitivity. Mol Pharmacol 48:63-71.

Margiotta J, Pugh P (2004) Nicotinic acetylcholine receptors in the nervous system. In: Molecular and cellular insights to ion channel biology (Maue RA, ed), pp 269-302. Amsterdam: Elsevier.

Marwitt R, Pilar G, Weakley JN (1971) Characterization of two cell populations in the avian ciliary ganglion. Brain Res 25:317-334.

Matter-Sadzinski L, Hernandez M, Roztocil T, Ballivet M, Matter J (1992) Neuronal specificity of the $\alpha 7$ nicotinic acetylcholine receptor promoter develops during morphogenesis of the central nervous system. EMBO J 11:4529-4538.

McAllister AK, Katz LC, Lo DC (1999) Neurotrophins and synaptic plasticity. Annu Rev Neurosci 22:295-318.

McGehee D, Heath M, Gelber S, Devay P, Role L (1995) Nicotinic enhancement of fast excitatory synaptic transmission in CNS by presynaptic receptors. Science 269:1692-1697.

McNerney M, Pardi D, Pugh P, Nai Q, Margiotta J (2000) Expression and channel properties of $\alpha$-bungarotoxin-sensitive acetylcholine receptors on chick ciliary and choroid neurons. J Neurophysiol 84:1314-1329.

Nagavarapu U, Danath S, Boyd RT (2001) Characterization of a rat neuronal nicotinic acetylcholine receptor $\alpha 7$ promoter. J Biol Chem 276:16749-16757.

Nai Q, Mcintosh JM, Margiotta JF (2003) Relating neuronal nicotinic acetylcholine receptor subtypes defined by subunit composition and channel function. Mol Pharmacol 63:311-324.

Nishi R, Berg DK (1981) Two components from eye tissue that differentially 
stimulate the growth and development of ciliary ganglion neurons in cell culture. J Neurosci 1:505-513.

Pardi D, Margiotta JF (1999) Pituitary adenylate cyclase-activating polypeptide activates a phospholipase C-dependent signal pathway in chick ciliary ganglion neurons that selectively inhibits $\alpha 7$-containing nicotinic receptors. J Neurosci 19:6327-6337.

Pizzorusso T, Ratto GM, Putignano E, Maffei L (2000) Brain-derived neurotrophic factor causes cAMP response element-binding protein phosphorylation in absence of calcium increases in slices and cultured neurons from rat visual cortex. J Neurosci 20:2809-28016.

Poo MM (2001) Neurotrophins as synaptic modulators. Nat Rev Neurosci 2:24-32.

Pozzo-Miller LD, Gottschalk W, Zhang L, McDermott K, Du J, Gopalakrishnan R, Oho C, Sheng Z-H, Lu B (1999) Impairments in high-frequency transmission, synaptic vesicle docking, and synaptic protein distribution in the hippocampus of BDNF knockout mice. J Neurosci 19:4972-4983.

Pugh PC, Berg DK (1994) Neuronal acetylcholine receptors that bind $\alpha$-bungarotoxin mediate neurite retraction in a calcium-dependent manner. J Neurosci 14:889-896.

Pugh P, Margiotta J (2000) Nicotinic acetylcholine receptor agonists promote survival and reduce apoptosis of chick ciliary ganglion neurons. Mol Cell Neurosci 15:113-122.

Rifkin JT, Todd VJ, Anderson LW, Lefcort F (2000) Dynamic expression of neurotrophin receptors during sensory neuron genesis and differentiation. Developmental Biology 227.

Rohrer H, Sommer I (1982) Simultaneous expression of neuronal and glial properties by chick ciliary ganglion cells during development. J Neurosci 3:1683-1693.

Role LW, Berg DK (1996) Nicotinic receptors in the development and modulation of CNS synapses. Neuron 16:1077-1085.

Rudy B, Kirschenbaum B, Rukenstein A, Greene LA (1987) Nerve growth factor increases the number of functional Na channels and induced TTXresistant $\mathrm{Na}$ channels in PC12 pheochromocytoma cells. J Neurosci 7:1613-1625.

Schnider AS, Poo M-M (2000) The neurotrophin hypothesis for synaptic plasticity. Trends Neurosci 23:639-645.

Schoepfer R, Conroy WG, Whiting P, Gore M, Lindstrom J (1990) Brain $\alpha$-bungarotoxin binding protein cDNAs and MAbs reveal subtypes of this brain of the ligand-gated ion channel gene superfamily. Neuron 5:35-48.

Schropel A, von Schack D, Dechant G, Barde YA (1995) Early expression of the nerve growth factor receptor ctrkA in chick sympathetic and sensory ganglia. Mol Cell Neurosci 6:544-566.
Schuman EM (1999) Neurotrophin regulation of synaptic transmission. Curr Opin Neurobiol 9:105-109.

Sharma G, Vijayaraghavan S (2003) Modulation of presynaptic store calcium induces release of glutamate and postsynaptic firing. Neuron 38:929-939.

Steljes TPV, Kinoshita Y, Wheeler EF, Oppenheim RW, von Bartheld CS (1999) Neurotrophic factor regulation of developing avian oculomotor neurons: differential effects of BDNF and GDNF. J Neurobiol 41:295-315.

Stone EM, Rothblum KN, Alevy MC, Kuo TM, Schwartz RJ (1985) Complete coding sequence of the chicken glyceraldehyde-3-phosphate dehydrogenase gene. Proc Natl Acad Sci USA 82:1628-1632.

Stoop R, Poo M-m (1996) Synaptic modulation by neurotrophic factors: differential and synergistic effects of brain-derived neurotrophic factor and ciliary neurotrophic factor. J Neurosci 16:3256-3264.

Takahashi T, Yamashita H, Nakamura S, Ishiguro H, Nagatsu T, Kawakami H (1999) Effects of nerve growth factor and nicotine on the expression of nicotinic acetylcholine receptor subunits in PC12 cells. Neurosci Res 35:175-181.

Tyler WJ, Perrett SP, Pozzo-Miller LD (2002) The role of neurotrophins in neurotransmitter release. Neuroscientist 8:524-531.

Vernallis AB, Conroy WG, Berg DK (1993) Neurons assemble AChRs with as many as 3 kinds of subunits while maintaining subunit segregation among subtypes. Neuron 10:451-464.

von Bartheld CS, Williams R, Lefcort F, Clary DO, Reichardt LF, Bothwell M (1996) Retrograde transport of neurotrophins from the eye to the brain in chick embryos: roles of the $\mathrm{p} 75^{\mathrm{NTR}}$ and trkB receptors. J Neurosci 16:2995-3008.

Wescamp G, Reichardt LF (1991) Evidence that biological activity of NGF is mediated through a novel subclass of high-affinity receptors. Neuron 6:649-663.

Wonnacott S (1997) Presynaptic nicotinic ACh receptors. Trends Neurosci 20:92-98.

Yeh JJ, Ferreira M, Ebert S, Yasuda RP, Kellar KJ, Wolfe BB (2001) Axotomy and nerve growth factor regulate levels of neuronal nicotinic acetylcholine receptor a3 subunit protein in the rat superior cervical ganglion. J Neurochem 79:258-265.

Ying SW, Futter M, Rosenblum K, Webber MJ, Hunt SP, Bliss TV, Bramham CR (2002) Brain-derived neurotrophic factor induces long-term potentiation in intact adult hippocampus: requirement for ERK activation coupled to CREB upregulation and Arc synthesis. J Neurosci 22:1532-1540. 